Rhode Island College

Digital Commons @ RIC

$1-1-2014$

\title{
Surgical Skills for the APRN Student: A Low-Fidelity Simulation Experience
}

Jason C. Heath

Rhode Island College

Follow this and additional works at: https://digitalcommons.ric.edu/etd

Part of the Other Education Commons, and the Perioperative, Operating Room and Surgical Nursing Commons

\section{Recommended Citation}

Heath, Jason C., "Surgical Skills for the APRN Student: A Low-Fidelity Simulation Experience" (2014). Master's Theses, Dissertations, Graduate Research and Major Papers Overview. 237.

https://digitalcommons.ric.edu/etd/237

This Major Paper is brought to you for free and open access by the Master's Theses, Dissertations, Graduate Research and Major Papers at Digital Commons @ RIC. It has been accepted for inclusion in Master's Theses, Dissertations, Graduate Research and Major Papers Overview by an authorized administrator of Digital Commons @ RIC. For more information, please contact digitalcommons@ric.edu. 
Surgical Skills for the APRN

Student: A Low-Fidelity Simulation Experience

by

Jason C. Heath RN, BSN, CRNFA

A Major Paper Submitted in Partial Fulfillment of the Requirements for the Degree of

Master of Science in Nursing

in

The School of Nursing

Rhode Island College

2014 


\begin{abstract}
There are many contemporary areas of practice available to the ACNP to date that encompass a surgical component of practice. Surgical specialty settings require a practitioner to be competent in a specialized base of knowledge as well as possess a fundamental set of psychomotor skills to practice competently. Unlike the training of the PA, ACNP programs do not typically address surgical theory or skills. The purpose of the program was to increase graduate nursing student confidence in basic surgical skills. The review of the literature examined the differences between the educational preparation of the PA and the NP, expansion of the NP role in surgery, as well as the use of simulation in graduate nursing education. The program incorporated a surgical skills lab concluding with a low-fidelity simulation experience. Skills addressed included the surgical hand scrub, donning surgical attire, and simple wound closure techniques. The sample comprised of 13 subjects representing $65 \%$ of the population meeting the inclusion criteria. The program was evaluated using a researcher designed and validated non-experimental Likert type survey measuring subject confidence both pre and post intervention. Responses to the nine Likert scale questions demonstrated a statistical increase from the pre-intervention to the post-intervention survey. Two participants reported utilized the new attained knowledge and skills during their final semester surgical clinical practicum. Incorporating surgical theory and skill training into graduate nursing education is vital if the ACNP would like to remain competitive with the PA in the surgical specialty job market.
\end{abstract}




\section{Table of Contents}

Table of Contents.................................................

Statement of the Problem............................................... 1

Literature Review................................................... 5

Theoretical Framework.................................................. 20

Method................................................................ 24

Results.................................................................. 41

Summary and Conclusions.......................................... 44

Recommendations and Implications for Advanced Nursing Practice ........... 48

References.......................................................... 51

Appendices........................................................... 55 


\section{Statement of the Problem}

The 1980's and 1990's was a period of time in healthcare dominated by the growth of physician specialists. The physician's trained in this era began seeking out highly educated and skilled technical assistants to both meet the needs of their growing patient population as well as become more efficient healthcare providers (Cooper, 2007). Non- physician healthcare providers who perform assessments, diagnosis, and treatment of disease processes either in collaboration with the physician or independently, became referred to as physician extenders. As in the past, the need of physician extenders in acute care specialty areas of practice continues today. The need can be explained by both the expected surge of new patients resulting from the Patient Protection and Affordable Care Act and the recent limitations placed on medical resident work hours (Aleshire, Wheeler, \& Prevost, 2012, Ponte \& O’Neill, 2013). The Nurse Practitioner (NP) and the Physician Assistant (PA) are two disciplines of non physician healthcare providers prepared to fill this need.

Like the first PA programs, formal NP programs were developed in the mid 1960 's to meet the primary care needs of the family residing in rural areas across the United States (US) (Bednar, Atwater, \& Keough, 2007). Since that time, both the education and roles of the NP and the PA have expanded to include the diagnosis and treatment of disease processes in all age groups and in an array of settings. As different as their educational preparation may be, in many instances the NP and the PA function in similar roles, under similar job descriptions, and are often credentialed together within 
the same institution (Bednar et al., 2007). The PA has long been a professional colleague to the NP as well as a competitor in the job market.

There are many contemporary areas of practice available to the Acute Care Nurse Practitioner (ACNP) to date. A survey focusing on the ACNP, which concluded in 2010, by the American Academy of Nurse Practitioners (AANP) identified many of these areas. Areas of specialty practice included critical care, trauma, general surgery, hospitalist, neurosurgery, interventional radiology, cardiology/cardiac catheterization lab, emergency department, pulmonary, neurology, orthopedics, wound care, pain management, oncology, gastroenterology, hematology, endocrinology, dermatology, and infectious disease (Kleinpell, Hudspeth, Scordo, \& Magdic, 2012). Of these specialty practice areas, many encompass a surgical component. Surgical specialty settings require a practitioner to be competent in a specialized base of knowledge as well as possess a fundamental set of psychomotor skills to practice competently.

Fundamentals of surgical practice is a mandatory component of the educational preparation of the PA however almost completely absent from the preparation of the ACNP. Psychomotor skill instruction found most frequently in ACNP programs across the US include: 12 lead ECG interpretation, chest X-ray interpretation, hemodynamic monitoring, simple suturing, spirometry \& peak flow assessment, local anesthesia application, Papanicolaou smear test, central venous line insertion, arterial puncture/cannulation, and intracranial pressure monitoring (Kleinpell, Hravnak, Werner, \& Guzman, 2006). Few of these skills are addressed in the Rhode Island College (RIC) ACNP program and even fewer are relevant in the surgical setting. Historically, the 
ACNP interested in pursuing a career in a surgical setting would be required to enroll in a Registered Nurse First Assistant (RNFA) program (Schroeder, 2008). Many RNFA programs integrate NP competencies into the curriculum (Schroeder, 2008). The process can be unappealing to a practicing NP or new graduate NP because of the time commitment as well as the cost involved. The lack of knowledge base and psychomotor skills related to surgery places the ACNP at a great disadvantage if seeking employment in a surgical specialty setting.

Dahring (2013) reports that in 2012, employers started to aggressively seek NPs for specialty hospital based and surgical practices which were once dominated by the PA. Trends of this nature are predicted to continue in the future (Dahring, 2013). A voluntary survey addressing the NP and PA salary by practice setting was published in 2013 . The survey was implemented by a non-academic journal catering to both the NP and the PA professions. A response was drawn from 3,723 NPs and 1,128 PAs (Advance for NPs \& PAs, 2013). The survey resulted in $11.51 \%$ of the PA respondents reporting practicing in a surgical setting whereas only $1.95 \%$ of the NP respondents reported practicing in the same setting (Advance for NPs \& PAs, 2013). Not only did the survey show a significantly lower number of NP's practicing in the surgical setting but also revealed that NPs earned a 9\% lower average salary than their PA colleagues (Advance for NPs \& PAs, 2013). The relatively small number of NPs practicing in the area of surgery and the lower reported salaries cannot be completely explained by the lack of surgical education delivered by the ACNP programs, however it remains a factor that must not be ignored. 
Integrating perioperative theory and fundamental psychomotor skills into the current ACNP curriculum may have a positive effect on the future of the ACNP and the RIC Graduate School of Nursing (SON). The surgical theory will provide the ACNP student with a basic knowledge of aseptic technique to draw upon in the future even if not practicing in the surgical setting. Coupled with the perioperative theory, the psychomotor skills will prepare the ACNP student to seek out opportunities to further their knowledge during their clinical practicum and professional practice. This action is vital for the ACNP to remain competitive in the future with the PA in the surgical specialty settings. The purpose of the program was aimed at increasing confidence in basic surgical skills among RIC graduate nursing students. The student researcher facilitated an educational intervention to prepare students for further clinical experiences and possible future practice in a surgical specialty area. 


\section{Literature Review}

The review of literature is broad in nature and attempts to uncover differences in the education preparation of the NP and the PA, explores the role expansion of the ACNP, identifies current Association of periOperative Registered Nurses (AORN) recommendations and position related to the advanced practice registered nurse (APRN) in the surgical setting, and investigates the use of simulation in graduate nursing education. Literature reviewed was discovered through the use of online databases and reference pages of previously reviewed articles. Databases searched included Cumulative Index to Nursing and Allied Health Literature (CINAHL), Medline, and Pub Med. Keywords for the search included nurse practitioner, physician assistant, education, low-fidelity simulation, scope of practice, perioperative practice, and surgery.

Publications included in the review are dated from the year 2004 to present.

\section{Educational Preparation}

Although the professional practice of the NP and the PA has developed into one that tends to mirror the other, the differences in the education and background of its professionals are well documented. An exploratory descriptive study conducted in 2007 examined many important differences in the educational preparation of the NP and the PA (Bednar et al., 2007). The author utilized a convenience sample technique to examine and compare $50 \mathrm{NP}$ and 50 PA programs. Bednar et al. (2007) did identify that the study was limited by the relatively small sample size. The study revealed five major differences between NP and PA educational preparation. The five differences included model of 
training, entry requirements for the NP and PA programs, entry level into the profession, didactic content and clinical hours (Bednar et al., 2007).

Differences in educational preparation begins with basic educational philosophy. The PA is educated under the medical model of care which is generally a more problem specific approach of diagnosis and treatment of health concerns. The NP is educated under one of the many nursing models of care that tend to have a patient centered holistic approach to care and greater focus on disease prevention. The holistic approach includes the assessment and treatment of specific disease processes as well as the numerous emotional, financial, and social effects that are present. The study reported that 21 of the institutions included in the sample prepared both the NP and the PA. Bednar et al. (2007) states, "Although many of the programs are existing side by side at the same university, there is very little integration of the students between the two programs" (p. 165). In fact, only two institutions were found to integrate the NP and PA coursework within the same curriculum (Bednar et al., 2007).

The requirements for admission to an NP and a PA program are the second area of program discrepancy identified. It was generally required that an NP student enter a program of study with a basic preparation in nursing which includes an active state Registered Nurse (RN) license. The Bachelor of Science in Nursing is the degree considered basic preparation in the study. In addition, many of the NP programs nationwide require 2000 - 4000 practice hours of experience as a RN prior to admission. The PA programs generally require a bachelor's degree including coursework in premedical sciences prior to admission. The authors identify that many of the PA 
programs strongly recommended previous healthcare related experience as well (Bednar et al., 2007).

The third area of difference between the two paths of education is entry level into practice. Throughout the years, many pursuing careers in both the NP and PA profession have been prepared through varying avenues. The entry levels of practice are currently in the process of change for both disciplines. The Accreditation Review Commission on Education for the Physician Assistant, the accrediting body for all PA programs in the US, formally identifies its requirements in the $4^{\text {th }}$ edition of the Accreditation Standards for the Physician Assistant Education publication. The Accreditation Review Commission (2010) states that "Programs accredited prior to 2013 that do not currently offer a graduate degree must transition to conferring a graduate degree, which should be awarded by the sponsoring institution, upon all PA students who matriculate into the program after 2020" (p. 2). The individual state boards of nursing and their individual Nurse Practice Acts are the regulating bodies controlling entry into practice for the NP. In 2008, a consensus model for APRN regulation was completed by the APRN Consensus Work Group in conjunction with the National Council of State Boards of Nursing (NCSBN) APRN Advisory Committee. This regulatory model stipulates "For entry into practice and for regulatory purposes, APRN education must: be formal education with a graduate degree or post-graduate certificate (either post-master's or post-doctoral) that is awarded by an academic institution and accredited by a nursing or nursing-related accrediting organization recognized by the U.S. Department of Education and/or the Council for Higher Education Accreditation” (APRN Consensus Work Group 
$\&$ the National Council of State Boards of Nursing APRN Advisory Committee, 2008, p. 11). It is suggested in the report that 2015 be the target year for full implementation of the consensus model (APRN Consensus Work Group \& the National Council of State Boards of Nursing APRN Advisory Committee, 2008). At the same time the American Association of Colleges of Nursing (AACN) is attempting to take the minimum level of education for entry into advanced practice a step further. The AACN (2004) proposes that the practice doctorate be the entry level graduate degree conferred for advanced practice nursing in the future. The organization also proposes the year 2015 as the date in which the recommendation should be implemented (AACN, 2004).

In relation to the differences in didactic content, the differences have been found to be greatest in the naming of the courses. The study by Bednar et al. (2007) found that the majority of the core courses taken by both groups to be nearly identical and that both groups have a solid academic foundation in science, diagnosis and management of disease processes, health promotion, and disease prevention. Where there were differences, however, they were great. The NP education was found to be lacking in the areas of anatomy, clinical procedures, surgery, emergency medicine, EKG interpretation, and X-ray interpretation. The study revealed that only $2 \%$ of NP programs included skills such as EKG and X-ray interpretation in the program. As to be expected, the PA curriculum was found to be lacking instruction on topics related to nursing theory in $100 \%$ of the sample studied (Bednar et al., 2007).

The final area of discrepancy in the preparation of the two disciplines reportedly lies in clinical practice hours. The PA educational requirement includes a student 
commitment of one full year to clinical training. As Bednar et al. (2007) discovered, clinical rotations add up to a mean of 2078 hours when calculated from this particular sample. Bednar et al. (2007) findings are significantly different for the NP who may complete the education on a part time basis and often over an extended period of time. The mean number of NP clinical hours reported in this study was found to be 658 (Bednar et al., 2007). The clinical hour component of the study was a part that authors recognize as being the most difficult to evaluate. Bednar et al. (2007) further acknowledged many possible various ways that the NP could calculate prior undergraduate clinical and professional $\mathrm{RN}$ practice experience to equal if not surpass the clinical hours of the PA. Comparing the clinical components of the two programs using these skewed numbers would be futile and invalidate the data. Bednar et al. (2007) believes that the NP student's previous experience, although critical to their success, does not qualify as advanced practice.

\section{Role Expansion}

Hiring a NP versus a PA is a question that is generally answered by either an administrator's or physician's prior experience with each profession. Ponte and O'Neill (2013) recognized this phenomenon taking place at a major cancer center located in the north-east recently and questioned its efficacy. At this specific site, there were 68 practicing physician extenders including 56 NPs and 12 PAs. In an effort to increase productivity and capacity for new patient visits, administrators sought out the answer of

why they preferred the NP over the PA. A study examining both roles was conducted by an interdisciplinary workgroup made up of the chief nursing officer, the chief medical 
officer, and the nurse executives of the major clinical areas in which the NP and the PA practice (Ponte \& O’Neill, 2013). Data was gathered through a review of the literature, individual interviews within the institution including the NP, PA, physicians, and interviews of colleagues in other regional organizations in an effort to obtain benchmark data on hiring practices. Ponte and O’Neill (2013) concluded that "disease centers should interview a range of candidates and select whichever applicant, NP or PA, best fits the position requirements based on an assessment of each candidate's experience, aptitude, knowledge, and abilities" (p. 333). Using these new hiring practices, the cancer center expects that hiring teams will have more freedom to select individuals that are a better fit for the organization rather than on the NP or PA credential alone (Ponte \& O'Neill, 2013).

Scope of practice (SOP) is a topic in advanced practice that is legally important, vague, and confusing to most. The APRN Consensus Work Group \& the NCSBN APRN Advisory Committee defines SOP as a set of rules, regulations, and boundaries within which a fully qualified NP may practice. As reported by Kleinpell et al. (2012), NP's do not enjoy the same common SOP and cross border consistencies that are afforded to the $\mathrm{RN}$, physician, and the PA. Individual states draft a nurse practice act with accompanying rules and regulations which are used to define the NP SOP. The Consensus Model, developed by the APRN Consensus Work Group \& the NCSBN APRN Advisory Committee, identifies that the NP SOP should in part be determined by one of the six population groups in which their APRN education was based upon. Additionally, the Consensus Model does not advocate for SOP regulations based on 
practice setting, but rather on patient healthcare needs (APRN Consensus Work Group \& the NCSBN APRN Advisory Committee, 2008). State nurse practice acts do not routinely identify specific tasks or procedures that may or may not be performed by the NP. Regulations are generally controlled by the facility that credentials the provider as a result of the ever changing world of healthcare and technology (Kleinpell et al., 2012). Kleinpell et al. (2012) believe professional associations that represent specific specialties are the organizations most knowledgeable of contemporary practice, are recognized as the expert source for tracking healthcare trends, and therefore are in ideal positions to make recommendations on NP SOP. Ultimately, "it is the professional responsibility of the NP to self-assess the appropriateness of their individual educational preparation, their demonstrated competency as evidenced by the certification they hold, and their legally authorized SOP granted by their state license and by the institutional credentialing process, and to match those with the identified patient care need they are seeking to meet" (Kleinpell et al., 2012, p. 17).

The AORN is the professional nursing organization that guides perioperative nursing practice. AORN officially recognizes and supports the role of the APRN in the perioperative setting (AORN, 2013). As Schroeder (2008) identifies, the role of the APRN in the perioperative setting is ideally suited to perioperative nurses and the Registered Nurse First Assistants (RNFA) who desire to take on an advanced practice role. The RNFA is currently an unrecognized advanced practice role in the field of nursing and unfamiliar to both the RN and NP. Students and professionals without a perioperative specific background should not be discouraged from exploring a surgical 
area of practice however. AORN considers a formal RNFA training program the gold standard for training the operating room naïve APRN, as well as the experienced perioperative RN, to assume the role of the first assistant (Schroeder, 2008). Formal RNFA training programs are identical for both the RN and the APRN and are based upon an AORN established core curriculum. The RNFA training program is a recommendation from AORN, not a requirement. Obtaining formal RNFA preparation can be valuable to the APRN when attempting to defend their scope of practice in litigation or in obtaining medical staff privileges. If attending a formal RNFA program is not an option, it is appropriate for a perioperative clinical nurse specialist or educator to instruct the ACNP on basic intra-operative skills to enhance patient safety prior to entering into the first assistant role (Schroeder, 2008).

A study published in 2005 by a well-respected perioperative author examined the pre-existing level of competence in fundamental perioperative nursing care among 16 APRN students enrolled in a community college based RNFA program (Rothrock, 2005). Of the 16 subjects in this study, 10 had no prior perioperative experience. Utilizing a self-rating instrument, those subjects with no prior perioperative experience identified 11 areas of knowledge deficit. Specific areas of knowledge deficit included:

- Establishing intra-operative nursing diagnosis and patient outcomes

- Developing an intra-operative plan of care (organizing nursing activities to function efficiently as the first assistant, knowing instruments, supply, and equipment needs)

- Positioning the patient for the surgical intervention 
- Creating and maintaining a sterile field

- Anticipating what would be required during the surgery

- Performing counts of sponges, sharps, and instruments to prevent the risk of injury from a retained foreign body

- Participating in use of surgical medications

- Calculating blood loss

- Monitoring and controlling the surgical environment (including traffic patterns, electrical safety, environmental sanitation, and thermoregulation)

- Exercising safe judgment and decision-making based on past experience

- Evaluating desired patient outcomes for the intra-operative period (Rothrock, 2005, p.6)

Rothrock (2005) identifies that these self-identified gaps in knowledge demonstrate the need for additional training of the OR naïve ACNP. AORN recognizes this concern in their published APRN Position Statement. AORN suggests that the education preparing the APRN to function as a first assistant in the surgical setting should, at a minimum, include the following content:

- Content that builds on the APRN's education in a specialty that has prepared the APRN to function in the preoperative and postoperative care of the surgical patient.

- Prepare the APRN to function in the intra-operative phase of the perioperative process. 
- Didactic and clinical component preparing the APRN to utilize instruments and medical devices, provide surgical site exposure, handling and cutting tissue.

- Anesthesia

- Aseptic technique

- Energy devices (electrical surgical unit and laser)

- Endoscopic surgery

- Hemostasis, sponges, and drains

- Latex allergy

- Positioning the patient

- Safety in the surgical suite

- $\quad$ Scrubbing, gowning, and gloving

- Skin preparation

- $\quad$ Specimen management

- $\quad$ Surgical draping

- Suturing, wound closure, and healing (p.300)

Additionally, AORN recommends that institutions ensure the APRN has the required education, training, experience, physical and mental health, and skill to function in the prospective role to both establish and maintain privileges to practice (AORN, 2013).

\section{Use of Simulation in Graduate Nursing Education}

Professional training through the use of simulation began in the 1930's by the US military and the aviation industry (Bednar, Atwater, \& Aitchison, 2011). Today, simulation is more of a standard in the training of professionals functioning in high-risk 
industries. The healthcare industry is no exception. The literature base examining various methods of simulation in the training of physicians, PAs, and undergraduate nursing students is quite broad compared to that of the APRN (Kelly \& Fry, 2013). This fact is striking given that the APRN acquires less formal clinical training, are utilized in many of the high risk specialty areas, and are expected to deliver care equal or greater to that of the other disciplines.

The use of simulation in the literature has been divided into one of three modalities. Low-fidelity simulation (LFS) makes use of basic task trainers, bench models, and low technology interventions. Mid-fidelity simulation (MFS) embraces the use of computer programs or video games in the learning experience. Finally, there is high fidelity simulation (HFS). This variety of simulation utilizes either a computerized human patient simulator manikin or biologic tissue within the training environment (Harder, 2010). What is consistent among all three modalities of simulation is their main goal to provide a realistic environment suitable to learning in an effort to increase safety, decrease errors, improve clinical judgment, and be useful in teaching and evaluating clinical skills (Harder, 2010).

A study published in 2013 examined graduate nursing students perceptions of a newly implemented simulation education experience. The retrospective, qualitative, exploratory study was conducted over a two year period (Kelly \& Fry, 2013). A convenience sample of 21 subjects, comprised of graduate nursing students, was identified in this study. Two researchers independently read, coded, and interpreted data from subject's de-identified essays. Collectively, the researchers analyzed data and 
developed 3 major themes. The first dealt with team building and meaningful work. Kelly and Fry (2013) report that $95 \%$ of the students felt that the simulation exercises produced a positive learning experience. A majority of the subjects reported productive use of communication, negotiation, and cooperation, all of which are elements contributing to effective team building. The second theme identified that the new course format provided a supported, realistic, and extended learning opportunities. The students included in the sample reportedly valued the guidance, safe environment, and collaborative feedback that aided in their learning during the course. The last theme highlighted the great benefit students felt resulted from the sharing of clinical experiences. Study data discovered that students valued basing simulation scenarios on shared personal experiences. Combining simulation with personal experiences was thought to create a more authentic learning opportunity (Kelly \& Fry, 2013). The authors believe the study provides evidence of the applicability of simulation, as a component of an innovative educational strategy, for both theoretical requirements and clinical benefit. Overall, the study confirms that masters nursing students identify simulation as a positive learning strategy that can effectively bridge the theory-practice gap (Kelly \& Fry, 2013).

Much of the new literature involving graduate nursing education and simulation focuses on the effects of HFS in comparison to non-simulation methods of instruction. Most HFS have a significant cost attached and utilize a great amount of resources while in use (Norman, Dore, \& Grierson, 2012). The cost can exhaust such resources and place a financial burden on many institutions. Using a non-systematic review of the literature, Norman et al. (2012) examined studies that contrast learning based on level of fidelity in 
attempt to investigate the extent to which greater fidelity leads to greater transfer of knowledge. The study was conducted in medicine and reviewed evidence from 18 previously conducted studies and systematic reviews. Three broad topics were examined including auscultation skills using heart sound simulators, basic surgical motor skills, and complex crisis management. The results show that when comparing the effect of training individuals on a high-fidelity simulator with no treatment, regarding auscultation skill training, the statistical gain was greatest. A smaller increase of $4.5 \%$ was noted in those trained on high-fidelity simulators as compared to individuals trained on clinical patients. When comparing groups trained on high fidelity simulators and low-fidelity simulators the difference was statistically smallest, resulting in a gain of $2 \%$. Studies comparing basic surgical skills revealed those trained on a high fidelity training model in comparison to no active training appreciated a statistical gain of $12 \%$. The effects of surgical skill training using a HFS in comparison to a LFS revealed a minimal statistical difference and resulted in a gain of only $1 \%$. Training in the area of critical care found differences between using HFS versus LFS greatest. There was a statistical gain of $4.4 \%$ found in the HFS group. Norman et al. (2012) explained this finding by identifying one of the studies reviewed as a statistical outlier. When the outlying study was removed from the statistical analysis the statistical gain in the HFS group equaled $1.5 \%$. Norman et al. (2012) summarizes the findings by stating "when the outcomes afforded by the HFS are compared with those of LFS, the gains of HFS are more modest and, almost without exception, are not statistically significant” (p. 644). 
High-fidelity and low-fidelity are terms that have slightly different meanings when used in surgical skill training. HFS generally refers to the use of biologic tissue, either living or deceased, derived from either an animal or human (Norman et al., 2012). LFS refers to the use of any non-biologic materials that are meant to produce an anatomic representation.

Denadai, Oshiiva, \& Saad-Hosse (2012) conducted a qualitative randomized controlled medical study examining the effects of bench model fidelity on acquisition of suture skills in medical students. A total of 36 subjects were included in the study and were considered novice medical students studying at a medical school in Brazil (Denadai, Oshiiwa, \& Saad-Hossne, 2012). A convenience sample was randomly divided into three groups of 12 subjects. The three groups were instructed on how to perform both a simple interrupted suture as well as a simple sub dermal interrupted suture during a lecture utilizing video. After one hour, group 1 received additional faculty instruction utilizing written and video materials. Group 2 practiced suturing techniques utilizing the lowfidelity bench model. Group 3 practiced suturing techniques on a high-fidelity bench model. Subject performance was measured by two blinded surgical specialist with no prior knowledge of the groupings. The evaluation method measured subject's performance closing two elliptical incisions measuring $8 \mathrm{~cm} \mathrm{X} 2 \mathrm{~cm}$ each utilizing five simple interrupted stitches and five sub dermal interrupted stitches on ox tongue with a five minute time limit. The author concluded that the acquisition of skills of both two and three dimensional sutures by novice medical students on the low-fidelity simulator was similar to the practice on the high-fidelity simulator after one hour of training, and 
the improvement of suture performance by participants trained on both simulators was greater than those who used theoretical materials (Denadai et al., 2012).

Confidence is a measurement in simulation that is highly regarded in nursing education. Studies assessing confidence while also utilizing methods of simulation with APRN students are lacking. Tiffen, Graf, and Corbridge (2009) did just this in their pilot study. The study was conducted at a large university nursing program and aimed to assess whether a LFS experience in an advanced health assessment class would improve confidence in heart and lung assessment skills among NP and Clinical Nurse Specialist (CNS) students. A convenience sample of 32 first year NP and CNS students were recruited to participate in the study. An experimental design was used and subjects were randomly assigned to either an experimental or control group. The students in the experimental group received a one-time session, lasting approximately 1 hour, with the patient simulator focusing on assessment of heart and lung sounds. The students in the control group received no training on the simulator and practiced cardiovascular and respiratory assessment during normal lab time. Results were obtained through subject self-assessment using a researcher developed confidence survey. Results revealed student confidence in relation to the assessment of heart and lung sounds was significantly higher among students who participated in a simulation experience versus students in the control group. Utilizing the Hotelling's $\mathrm{T}^{2}$ test the findings were found to be statistically significant (Tiffen et al., 2009). The study ultimately indicates that the use of LFS can positively affect the confidence in assessment skill acquisition of graduate nursing students. 


\section{Theoretical Framework}

The student researcher identified two frameworks that provided the foundation for this educational program. Malcolm Knowle's theory of adult learning, borrowed from the field of education, is often referred to as the androgogical model of learning. Androgogy is defined as "the art and science of helping adults learn" (Knowles, Holton III, \& Swanson, 2005, p. 61). The process model for learning views the teacher as a facilitator of learning (Knowles et al., 2005). Within the framework, the facilitator's duty is to prepare a set of eight procedures designed to involve adult learners in the process of learning. The key procedures include: preparing the learner; establishing a climate conducive to learning; creating a mechanism for mutual planning; diagnosing the needs for learning; formulating program objectives that will serve to satisfy identified needs; designing a pattern of learning experiences; conducting these learning experiences with suitable techniques and materials; evaluating the learning outcomes and rediagnosing learning needs. Knowles et al. (2005) recognizes that the androgogical model is not concerned with the transmission of specific information or skills, rather with providing procedures and resources assisting learners acquire information and skills. Key to the androgogical model, Knowles et al. (2005) identified six assumptions regarding adult learners:

1. The need to know: Adults need to know why they need to learn something before undertaking to learn it. 
2. The learner's self-concept: Adults have a self-concept of being responsible for their own decisions. Learning experiences necessitate a less dependent and more self-directed environment.

3. The role of learner's experiences: As people mature they accumulate a large amount of experience that can serve as a rich resource for learning.

4. Readiness to learn: Adults become ready to learn those things they need to know and be able to do in order to cope effectively with their real-life situations.

5. Orientation to learning: Adults are motivated to learn to the extent that they perceive that learning will help them perform tasks or deal with problems that they confront in their life situations.

6. Motivation: Adults are responsive to some external motivators, but the most potent motivators are internal pressures. (p.64-68)

The student researcher assumed the role of "facilitator" during the entirety of the project. Planning stages of the program development stemmed from Knowles eight procedures to prepare the learner. Educational interventions and objectives were strongly influenced by Knowles et al. (2005) assumptions of adult learners.

The second framework utilized was a model of program development. With the permission of W.K. Kellogg Foundation, the Logic Model of program development guided the student researcher in the planning, implementation, and evaluation of the educational program. A logic model is defined as: "a systematic and visual way to present and share understanding of the relationships among the resources you have to operate your program, the activities you plan, and the changes or results you hope to 
achieve" (W.K. Kellogg Foundation [Kellogg Foundation], 2004, p. 1). Logic Models take on a variety of configurations and are known for their ability to demonstrate a program's goals and sequence of activities visually in a map like configuration. Figure 1 identifies both the individual components of the Logic Model as well as the relationship between each individual component. Five primary components of the Logic Model, as identified by the Kellogg Foundation (2004), are as follows:

1. Factors are resources and/or barriers, which potentially enable or limit program effectiveness.

2. Activities are the processes, techniques, tools, events, technology, and actions of the planned program.

3. Outputs are the direct results of program activities.

4. Outcomes are specific changes in attitudes, behaviors, knowledge, skills, status, or level of functioning expected to result from program activities and which are most often expressed at an individual level.

5. Impacts are organizational, community, and/or system level changes expected to result from program activities, which might include improved conditions, increased capacity, and/or changes in the policy arena. (p.8) 


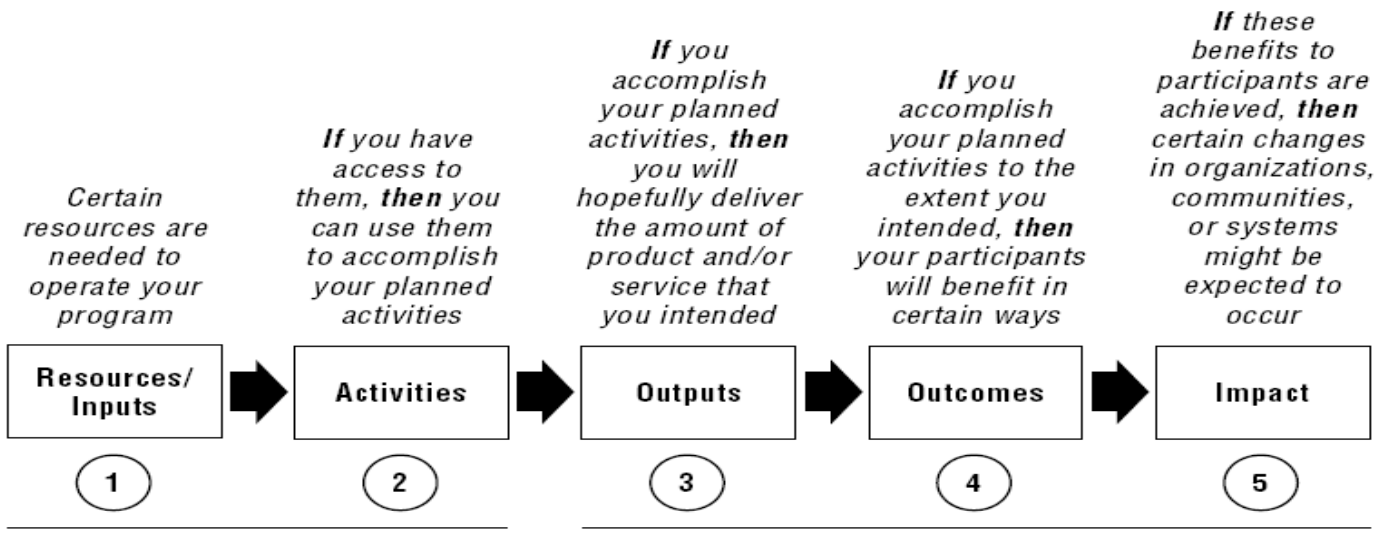

Your Planned Work

Your Intended Results

Figure 1. Five components of Logic Model. (Kellogg Foundation, 2004)

Use of a Logic Model assisted the student researcher in organization of resources as well as clear communication of planned work and intended results. Please refer to Appendix A to view A Logic Model developed for the program. 


\section{Method}

\section{Needs Assessment}

The needs assessment was conducted using a two tier approach. Watkins, Meiers, \& Visser, (2012) describes a needs assessment as a process that can be divided into three independent approaches, two in which the student researcher applied during the program's needs assessment include the strategic and tactical. The strategic approach is described as a process that assesses needs of a society. Focusing on results a program will contribute to society is paramount in the strategic approach. The tactical approach is described as a process that focuses on the needs of participants. A focus on results a program will deliver to its participants guides the tactical approach (Watkins et al., 2012).

The strategic approach was conducted almost entirely through review of literature. The literature clearly demonstrates, within the educational preparation of NPs nationwide, there is a lack of content in which would deliver the skills necessary to perform in a surgical setting. This finding is also consistent in the state of Rhode Island. The two higher learning institutions offering a NP track, University of Rhode Island and RIC, currently have no advertised courses pertaining specifically to perioperative practice. Aside from basic suturing, which is a skill not exclusive to surgery, this area of practice is not addressed in any of the courses offered. The fact that practicing in a surgical setting is well within the NP SOP has previously been established in this document. The literature also shows a much smaller percentage of NP's actively practicing in the surgical setting in comparison to their PA counterparts (Advance for NPs \& PAs, 2013). The program in no way intended to deliver all of the educational 
components necessary to prepare a NP for a career in surgery. Results of that nature would far exceed the scope of the program. In relation to society the program aimed to increase NP student confidence in basic surgical skills and generate interest the surgical practice area. The new found interest will in return lead to a greater percentage of NPs filling open surgical positions, increase in the delivery of quality nursing based healthcare to surgical patients, and greater number of clinical placements for NP students interested in a surgical experience in the future.

The tactical aspect of the needs assessment was undertaken in an attempt to define the specific content that the program delivered to participants. It is understood that the tactical approach of the needs assessment must align with the strategic aspect in order to successfully arrive at the desired program outcome (Watkins et al., 2012). Multiple techniques of data acquisition were utilized during this aspect of the needs assessment. Many individual skills were identified by the student researcher, who currently holds certification as an RNFA, which would potentially benefit the APRN student. The data assisted the student researcher in determining the individual skills that would both meet the needs of the subjects as well as align with the goals of the program.

The first technique of data acquisition included an informal survey of peers. During the brainstorming phase of developing the program the student researcher requested input by peers. Conversation led to the determination that there was no surgical experience among the group. The student researcher concluded, as a result of the group consensus, specific surgical skills possessed need not be surveyed. There was in fact great interest displayed among peers regarding a surgical skill educational program. 
Additionally, the student researcher reports that peers did express a specific interest in learning suturing techniques on multiple occasions.

The literature review contributed to this aspect of the needs assessment as well. Basic suturing techniques are listed among the top of the most frequently taught skills in ACNP programs. Kleinpell et al. (2006) also reports that approximately $73 \%$ of ACNP educators surveyed believe suturing should be included as a basic component of ACNP education. It is pertinent to mention that the RIC School of Nursing has historically integrated a skills lab day into the ACNP program which included training in basic suturing skills. AORN has addressed educational needs of the operating room naive APRN as well. Gaps in APRN knowledge are specifically identified in the position statement released in 2013 regarding the APRN practicing in the perioperative setting.

The student researcher conducted a personal interview to aid in the needs assessment process. A CNS holding a position of perioperative nurse educator at a local community hospital was contacted for this purpose. During the interview the student researcher identified that a component of the CNS's practice included the basic preparation and evaluation of all un-trained medical students, PAs, and NPs seeking clinical experience at her facility (personal communication, July 2013). The CNS further revealed that the training protocol for such a population includes two AORN produced video recordings and approximately one hour of clinical instruction. Specific training methods of instruction address the topics of aseptic technique, the surgical hand scrub, as well as surgical gowning and gloving. The CNS was further questioned in an effort to determine why these specific topics were selected. It was determined, in her expert 
opinion, that the specific topics included were the most primary of the knowledge and skills necessary to safely engage in educational experiences in the surgical setting. A prominent perioperative author and educator, Dr. Jane Rothrock, concurs with the CNS interviewed. Rothrock (2005) believes all APRNs enrolled in RNFA training programs should be pre-tested and demonstrate satisfactory perioperative skills specific to surgical aseptic technique prior to advancing to the clinical component of the program.

The student researcher opted for a specific set of educational interventions after weighing the advice of experts, considering educational guidelines established by AORN, and taking note of the interests of the adult learner. The surgical hand scrub, surgical gowning and gloving, and basic suturing techniques were the skills chosen to include in the program. The student researcher determined that the proposed skills will adequately prepare the learner for future educational experiences in a surgical area of practice, build upon knowledge previously attained in undergraduate education and professional nursing practice, and provide skills that will be transferrable to areas of practice other than surgery.

\section{Purpose}

The purpose of the program was aimed at increasing confidence in basic surgical skills among RIC graduate nursing students. The student researcher facilitated an educational intervention to prepare students for further clinical experiences and possible future practice in a surgical specialty area. 


\section{Program Design}

The program incorporated a surgical skills lab day concluding with a low fidelity simulation experience. Method of instruction included demonstration/return demonstration of psychomotor skills as well as informal lectures on topics relevant in the advancement of perioperative theoretical knowledge. Pre and post confidence surveys were utilized for program evaluation research purposes.

\section{Program Objectives}

The objective of the program was to deliver skills to graduate nursing students necessary to gain further educational experiences in a surgical setting. Individual objectives included:

- Increase knowledge pertaining to aseptic technique.

- Increase in confidence performing surgical hand scrub.

- Increase in confidence donning sterile surgical attire.

- Increase in confidence performing simple wound closures.

- Increase in confidence in subject own ability to gain further surgical experience during clinical training or in professional practice.

\section{Sample}

The student researcher utilized a non-probability purposive sampling technique in obtaining subjects. Inclusion criteria consisted of RIC graduate nursing students entering their final semester of study. There was estimated to be 20 subjects in all representing the NP, CNS, and public health tracks. No subject that fulfilled the inclusion criteria was 
excluded from participating in the program. The student researcher's goal was to have a participation rate of $80 \%$ which would result in 16 total subjects.

Site

The educational intervention and the survey of subjects took place within a graduate school of nursing at a state institution of higher education. The RIC SON, located in the Providence metropolitan area, is the home of both the largest baccalaureate nursing program in the state of Rhode Island as well as a recently established graduate school of nursing. The RIC graduate school of nursing presently offers two areas of study. The first is an adult/gerontology area of study focusing on acute care practice with both a CNS and an NP tract. The second is a population health/ public health area of study.

\section{Procedures}

RIC Institutional Review Board (IRB) application was submitted with the proposal October 7, 2013. IRB approval was granted on November 26, 2013 after minor revisions were made to the original proposal. Subject recruitment officially began with the distribution of the first of two advertisement flyers to all prospective subjects on November 27, 2013 (Appendix B). Prospective subjects include all RIC graduate nursing students entering their final semester of study. The flyer distribution occurred in two ways. The prospective NP and CNS subjects received their flyer from the student researcher on the RIC campus prior to the start of a formal class lecture. The prospective community/public health graduate students received their flyer by means of e-mail from the student researcher. The flyer consisted of an invitation to participate in the program, 
program objectives, notice of optional pre and post survey, and list of four possible dates identified by both the RIC SON and the student researcher. Subjects were encouraged to select a date which they believed to be most convenient and either return that portion of the flyer to an envelope or email a response to the student researcher. Two dates that best accommodated the student subjects and availability of the nursing skill lab were selected from this information for the month of January in the year 2014. A second flyer was distributed on December 18, 2013 which identified the two selected dates. Subjects were asked to select one of the two dates that was most convenient and email a confirmation to the student researcher if they were interested in participating.

The student researcher introduced himself on the two mornings of the interventions prior to any program activity, reiterated the nature of the project, distributed a schedule of the days planned activities, and an envelope containing the consent document as well as both the pre and post-intervention surveys. Both the student researcher and the advising faculty member exited the room while the RIC nursing resource lab coordinator read aloud the consent form in its entirety. The resource lab coordinator was instructed to specifically place emphasis on portions of the consent that addressed participation in the survey portion of the program as being optional, data gathered during the survey will be collected and stored in a de-identified fashion by the student researcher, and specific risks of participating in the educational program and survey. Prior to continuing all participants had adequate time to read the consent form, ask questions pertaining to the educational intervention and survey, and determine whether or not to participate. Those subjects willing to participate completed the survey 
and returned it to a collection envelope labeled pre-intervention. Those subjects choosing not to participate in the survey were encouraged to return a blank form to the envelope so that they were not identified by peers in effort to maintain subject confidentiality. Once all pre-intervention surveys were collected both the student researcher and advising faculty member re-entered the room and the educational intervention commenced.

The day began on the topic of hand asepsis. A traditional surgical hand scrub was demonstrated to the group by the student researcher. During the demonstration an informal discussion regarding the utility of the hand scrub, alternative methods of hand asepsis, common technique flaws of the novice and the expert, and other questions posed by the student subjects were addressed. The discussion was followed by a skill practice session. During the skill practice session subjects were guided by the student researcher in the completion of a surgical hand scrub and encouraged to ask questions freely. This activity took forty-five minutes.

The next activity focused on surgical attire. Informal discussion pertaining to the necessary components of surgical attire took place initially. Discussion addressed how this intervention built upon previously acquired knowledge of sterility and sterile gloving techniques. The student researcher modeled the surgical attire, demonstrated the sterile versus unsterile areas, and addressed the importance of proper upper body positioning in maintaining aseptic technique. The student researcher next demonstrated the proper procedure for donning a surgical gown and gloves utilizing the closed glove technique. The role of the non-scrubbed team member was addressed and demonstrated secondly. Questions were encouraged at the completion of the demonstration. Student subjects 
paired up and had the opportunity to practice the skill. Student subjects alternated practicing in both the scrubbed and non-scrubbed roles. The student researcher was available to further demonstrate the skills and assist the learner during the practice time. When student subjects were ready to continue, the program facilitator introduced a second method of donning a sterile gown and gloves. The technique of being gowned and gloved by a member of the surgical team was demonstrated by the student researcher. Demonstration focused on the proper technique of receiving a gown and gloves from a surgical team member at the sterile field. Each learner practiced being gowned and gloved by the student researcher and then subsequently by their partners. Discussion continued during this process covering the reasoning and importance of learning the two techniques. Maintaining asepsis and acceptable ways to move around a sterile field are topics that were also discussed and demonstrated once all learners had donned their gown and gloves. This activity took sixty minutes.

Surgical instruments necessary to complete the day's activities were introduced. The forceps (Adson or small rat tooth), needle driver, and scissor were presented and distributed to each of the student learners. Proper handling and usage of each were demonstrated by the student researcher. A practice session followed in which each learner was given the time to handle and become comfortable manipulating the three instruments. The student researcher answered many questions and guided the learners during the process of becoming familiar with the instruments. Once an acceptable comfort level had been reached by the group handling the instruments, the student 
researcher continued to the next activity. This activity took approximately fifteen minutes.

The skills necessary to execute a proper surgical knot was addressed. Two methods of knot tying were demonstrated by the student researcher. The learner had the opportunity to practice techniques demonstrated on student researcher designed lowfidelity suture trainers. The learners became skilled at each technique by initially utilizing an oversized colored string, and progressively moving toward materials that decreased in diameter and closer resembled suture material. The first demonstrated technique involved tying a two handed surgical knot. The student researcher demonstrated the technique and described hand movements in a step by step fashion. The demonstration of this technique continued and learners were encouraged to follow along with the program facilitator. Learners had the opportunity to progress to the smaller diameter materials at their own pace. The student researcher answered questions as well as discussed the system in which the diameter of suture is sized while practicing the skill. This activity took forty five minutes.

The student researcher next introduced surgical instruments into the skill of surgical knot tying. Instrument tying was first demonstrated to the group by the student researcher. The student researcher demonstrated the technique and described hand movements in a step by step fashion. Demonstration of this technique continued and learners were encouraged to follow along with the student researcher. Learners had the opportunity to progress to the smaller diameter materials at their own pace. The student researcher discussed the many differences in suture materials while practicing the skill. 
The discussion included braided versus monofilament suture, absorbable versus non absorbable, as well as answers to questions posed by the learners. The activity took approximately thirty minutes.

The combined the use of real suture materials, surgical instruments, and lowfidelity SynDaver ${ }^{\mathrm{TM}}$ suture trainers was exercised. Three basic stitches were demonstrated by the student researcher. All three of the stitches demonstrated are useful in a variety of settings, not solely the surgical setting. The three techniques demonstrated included the simple stitch, the simple stitch with a buried knot, and the horizontal mattress stitch. Techniques for each of these three stitches were demonstrated by the student researcher individually. While the technique for each stitch was demonstrated and described in a step by step approach by the student researcher, the learners were encouraged to follow along. Questions were answered and techniques continually demonstrated as necessary throughout skill practice time. The activity was completed in ninety minutes.

The day culminated with a low-fidelity simulation experience. The final activity allowed the learner to demonstrate a multitude of skills acquired from this program in one meaningful experience. The simulation experience included the performance of a surgical hand scrub, donning a surgical gown and gloves, and closing a simple wound while maintaining aseptic technique. The activity took place in a simulated operating room setting that included a simulated sterile back table and a simulated patient possessing SynDaver ${ }^{\mathrm{TM}}$ low-fidelity suture trainers at multiple sites. The student 
researcher was available to answer questions and guide the learners through this experience. The activity was completed in 60 minutes.

The skill lab concluded when the learner determined that the educational intervention had delivered a satisfactory experience. The student researcher and advising faculty member exited the room and all subjects had the opportunity to complete the postintervention survey if desired. Completed surveys were placed in a collection envelope by the subjects labeled post-intervention. Pre and post intervention survey envelopes were retrieved by the program facilitator once all subjects had departed the lab.

\section{Desired outcomes}

The educational program aimed to increase RIC graduate nursing student's confidence performing basic surgical skills and wound closure techniques. The student researcher anticipates that with an increase in confidence, students will utilize acquired skills and seek out future experiences in the surgical practice areas.

\section{Organizational/ systems factors}

Many factors positively contributed to the program. Success of the program depended greatly on the educational background and the skills possessed by the student researcher. The student researcher has been formally trained, certified, and has practiced as an RNFA for greater than 6 years. The student researcher has been committed to delivering quality perioperative nursing care to surgical patients for over 11 years. Even the most experienced perioperative nurse could not conduct a project of this magnitude without support. Faculty of the RIC SON were encouraging and supportive of the 
student researcher's proposed ideas. Their guidance during the development stages of the program and offering of resources surely enhanced the program's success.

Cost was a major concern while planning a project of this scale. The student researcher's intent was to procure a majority of supplies necessary to carry out the program through donations. A local community hospital had generously donated a great quantity of sterile expired goods in support of the program which greatly reduced the financial burden incurred by the student researcher. Funds were also secured from the RIC SON early in the program development phase by the student researcher's advising faculty member. These funds were utilized to purchase supplies unobtainable through donations. Other than cost, the major barrier identified involved the sample size. There were 20 students in total that met the inclusion criteria for the program. The student researcher deemed it necessary to accommodate the small number of potential subjects every way possible in effort to ensure a high turnout and deliver a meaningful program. Subject availability in comparison with the availability of the RIC nursing skills lab could have potentially led to a poor outcome.

\section{Human Subjects Considerations}

Graduate students of RIC SON are the subjects in this educational intervention/survey. The subjects are also the peers of the student researcher and students of the RIC faculty advisor assigned to the research project, therefore are considered a vulnerable population. RIC IRB approval was sought prior to enlisting subjects to the educational intervention/survey. The original date of submission to the RIC IRB was October 7, 2013 and the program was granted IRB approval November 26, 2013. The 
student researcher and IRB determined that the risk involved with participating in the surgical skills lab/survey was minimal and no greater than what might be experienced in a subject's normal daily life. All subjects were Registered Nurses as well as graduate students within RIC SON. These two specific backgrounds expose the study subjects to educational interventions, various methods of survey, and clinical experience on a fairly regular basis. Minimal risk does not equal zero risk. The student researcher had identified three potential risks in relation to the individual subjects and participation in the educational intervention/survey.

The first potential risk could be breach of confidentiality. Methods were in place during survey data collection to protect individual subject confidentiality. The methods included administration of the survey by the RIC nursing resource lab coordinator, the use of random control numbers on the survey tools, removal of student researcher and faculty advisor from the room during survey procedure, as well as instruction to return incomplete surveys to the collection envelope in effort to not be identified by peers as refusing to participate. Specific discussion during the informed consent procedure identified that inquiry of other participant's answers was not only considered unethical but could have also compromised the integrity of the collected data. Data that was deidentified prior to removal from the RIC campus to prevent the possibility of being linked to a specific individual.

The second risk related to the potential feeling of coercion produced by the student researcher or faculty advisor. In no way was it the student researcher's or RIC faculty advisor's intent to coerce fellow peers/students to participate in any portion of the 
program including research components. Participation in the program was completely voluntary and individual performance was in no way used by RIC faculty in formulating a semester grade or effect status within the RIC SON.

The third risk identified relates to physical harm. Whenever educational interventions include topics that involve handling of "sharps" there is an inherent risk of injury. In health care sharps are defined as any needles, scalpels, and other devices that have the potential to cause wounds, punctures, or any other percutaneous injury to personnel handling such devices. It is important to note that all suture materials utilized during the educational intervention were unused, clean, and sterility expired items. It is also important to note that the simulators utilized during the intervention were constructed of synthetic materials and 100\% non- biologic. Subjects were instructed to utilize universal precautions including hand washing and wearing surgical gloves while handling sharps. Used sharps were secured in surgical needle counter boxes. At the conclusion of activities all sharps were accounted for and disposed of appropriately. Chance of acquiring a disease causing microorganism during the educational intervention was found to be minimal due to the previously mentioned safety measures as well as the fact that the educational intervention was located outside a hospital environment. There was the possibility of subjects sustaining puncture wounds and/or percutaneous injuries during the educational experience. The subjects were all professional nurses and were adept in handling of "sharps" in their professional role making it reasonable to assume that the risk of physical injury was minimal and no greater than the subjects experience on a daily basis. Introduction to the skills of suturing in such a controlled environment is 
far safer than attempting to gain similar experience in a real life clinical scenario where risk would be increased exponentially.

The researcher's intent was to gain consent from subjects prior to initiating components of the educational intervention/survey. A comprehensive consent form was distributed to each subject with the survey and completion of the survey indicated implied consent. Each subject was encouraged to retain a copy of the informed consent document for their future reference. Subjects were instructed during the consent process to address concerns they had regarding any belief of being exposed to risk greater than desired or out of proportion from what had been described first with the student researcher and RIC faculty member advising this educational program/survey. Subjects who chose to pursue their concerns further were advised to contact the RIC IRB. Contact information was provided on the informed consent document.

\section{Program Evaluation}

The educational intervention was evaluated utilizing a non-experimental prospective survey. The student researcher, after an extensive literature review, concluded that there was no tool previously developed that measured the specific parameters desired in the program. The survey was therefore student researcher designed and validated. The survey consisted of 9 questions utilizing a 5 point Likert-type scale. The survey evaluated the learner's confidence both pre and post educational intervention. A scale of 1 through 5 was used, with $1=$ strongly disagree and $5=$ strongly agree. In addition, the post-intervention survey included two items pertaining to program evaluation and a third seeking comments and critique of the program by means of 
subjective data. The tool has been tested for face validity by seven clinicians among the surgical practice area and education. The 7 clinicians included representatives from the fields of nursing, medicine, and allied health professionals. Feedback was requested and adjustments were made to the tool prior to its use. Please see Appendix C for the preintervention survey and Appendix D for the post intervention survey.

\section{Plan for Dissemination}

The outcome of the program, including the results of the survey, will be reported at the conclusion of the spring 2014 semester. An oral presentation depicting both successes and failures of the program were presented at the graduate research dissemination seminar held at RIC. A complete description of the program and findings are available in print. The printed document is stored in the RIC library. 


\section{Results}

The sample was comprised of 13 subjects in all representing $65 \%$ of the population meeting the established inclusion criteria. The 13 subjects consisted of 1 male and 12 females. Subjects were exposed to the educational intervention in two groups. Group $A=4$ subjects and group $B=9$ subjects. The two groups were formed by subject choice of day to attend and both were exposed to identical procedures. One hundred percent of the attendees of the skill lab participated in the survey.

Responses to the nine Likert scale questions demonstrated a statistical increase from the pre-intervention to the post-intervention survey. Interest in furthering knowledge and skills necessary to practice in the surgical setting was demonstrated in the collected data. Ninety-two percent of the population responded "Agree" or "Strongly agree" to the question when asked pre intervention and $100 \%$ of the population responded "Agree" or "Strongly agree" post intervention. Question nine revealed, preintervention, that subjects did not possess the skills and required knowledge that would allow them to confidently seek out surgical experiences in future clinical rotations and professional practice. The response to the item pre-intervention resulted in $61 \%$ of the population selecting "strongly disagree". Post- intervention the same question was asked and $61 \%$ of the population then selected "Agree". Table 1 illustrates questions, the mean response pre and post intervention, as well as the overall change. All items resulted in an increase in mean score of 2.0 or greater with one exception. Item one surveying general interest in furthering surgical knowledge and skills demonstrated the smallest increase equaling 0.07 . 
Table 1.

Likert Scale confidence Survey Data

\begin{tabular}{|lccc|}
\hline \multicolumn{1}{|c}{ Survey questions } & $\begin{array}{c}\text { Pre- } \\
\text { intervention } \\
\text { mean score }\end{array}$ & $\begin{array}{c}\text { Post-intervention } \\
\text { mean score }\end{array}$ & Change in score \\
\cline { 2 - 4 } $\begin{array}{l}\text { I have an interest in gaining further knowledge } \\
\text { and skills necessary to practice in a surgical area. }\end{array}$ & 4.62 & 4.69 & +0.07 \\
$\begin{array}{l}\text { I am confident in my ability to perform a surgical } \\
\text { hand scrub. }\end{array}$ & 2.23 & 4.54 & +2.31 \\
$\begin{array}{l}\text { I am confident in my ability to don a surgical } \\
\text { gown and gloves using proper aseptic technique. }\end{array}$ & 2.08 & 4.54 & +2.46 \\
$\begin{array}{l}\text { I am confident in my ability to tie a proper } \\
\text { surgical knot using the two hand technique. }\end{array}$ & 1.69 & 3.69 & +2.00 \\
$\begin{array}{l}\text { I am confident in my ability to tie a proper } \\
\text { surgical knot using the instrument technique. }\end{array}$ & 1.85 & 4.38 & +2.53 \\
$\begin{array}{l}\text { I am confident in my ability to perform a simple } \\
\text { skin stitch. }\end{array}$ & 1.69 & 4.54 & +2.85 \\
$\begin{array}{l}\text { I am confident I my ability to perform a simple } \\
\text { subcutaneous stitch with a buried knot. }\end{array}$ & 1.54 & 4.46 & +2.92 \\
$\begin{array}{l}\text { I am confident in my ability to perform a } \\
\text { horizontal mattress stitch. }\end{array}$ & 1.38 & 4.31 & +2.93 \\
$\begin{array}{l}\text { I possess skills and required knowledge that will } \\
\text { allow me to confidently seek out surgical } \\
\text { experiences in future clinical rotations or }\end{array}$ & 1.69 & 4.23 & +2.54 \\
professional practice. & & & \\
\hline
\end{tabular}

\section{Program Evaluation}

Respondents were requested to provide subjective comments and criticism in relation to the program on the post intervention survey. Comments were received from 11 out of 13 participants. Comments included: "Great workshop! Valuable skills to use in my future practice", "Excellent! Happy to have these skills moving forward", and “This was an excellent and very well thought out skill lab. A great experience!" One subjective comment in particular did address a potential flaw in the program stating "A handout including a written description and diagram of skills would have been helpful. I loved this!" 
Two additional items were included on the post intervention survey. The two items sought to evaluate the program's resources, methods of instruction, environment, and whether knowledge obtained would be transferrable to settings other than surgery. Results are reported on Table 2.

Table 2.

Program evaluation data

\begin{tabular}{|c|c|c|}
\hline & Number & of responses \\
\hline Question & $\overline{Y e s}$ & No \\
\hline $\begin{array}{l}\text { I believe that the program utilized appropriate resources and methods } \\
\text { in the facilitation of learning? }\end{array}$ & 13 & 0 \\
\hline $\begin{array}{l}\text { I believe that the skills and knowledge acquired today will be } \\
\text { beneficial in practice areas other than surgery? }\end{array}$ & 13 & 0 \\
\hline
\end{tabular}




\section{Summary and Conclusions}

Research shows that there are a significantly lower number of NPs practicing in a surgical setting when compared to PAs. NPs practicing in a surgical setting are reportedly earning a significantly lower salary than their PA colleagues. Review of the literature revealed one possible explanation to the phenomenon. Although job descriptions of the NP and PA are quite similar, the educational preparation of both disciplines are quite different. The PA generally receives more in depth training related to psychomotor skills as well as mandatory surgical clinical rotations unlike the typical training of an NP.

The purpose of the student researcher developed educational program was aimed at increasing confidence in basic surgical skills among RIC graduate nursing students. Increased confidence in surgical skills was predicted to facilitate further educational and professional experiences in a perioperative setting. Delivery of content occurred during one of the two identical skill lab days offered. Method of instruction included informal discussion, skill demonstration, and return demonstration. Recruitment efforts resulted in a total of 13 subjects equaling $65 \%$ of the population meeting the inclusion criteria. Inclusion criteria required subjects to be graduate students entering their final semester of study at RIC SON. A Likert type survey was utilized both pre and post intervention in effort to evaluate the effectiveness of the program. The survey utilized a measurement of subject confidence in determining program effectiveness. In general there was an overwhelming positive response in respect to the program from both the student subjects 
and representatives of the RIC SON. Data collected strongly suggests the program objectives and desired outcomes were successfully met.

The program delivered a small amount of perioperative theory to all subjects. The student researcher touched upon perioperative topics such as aseptic technique, hand hygiene, suture materials, and tissue handling during informal discussions throughout the day. The theoretical knowledge was pre-determined by the student researcher to be vital to the successful completion and acquisition of skills presented during the program. Discussions produced many questions from subjects and stimulated critical thinking during performance of individual skills.

Psychomotor skills presented in the program included performance of a surgical hand scrub, donning sterile surgical attire, maintenance of aseptic technique, handling and use of surgical instruments, two methods of tying suture, and three individual stitches necessary in basic wound closure. Overall, the data revealed that there was a dramatic increase in subject confidence in all of the skills presented. Figure 2 demonstrates the increase in subject confidence. There were no instances of decreased level of confidence when comparing individual subject responses prior to intervention with those post intervention. The student researcher anticipates subjects will utilize acquired skills and seek out further experiences in the surgical practice areas with increased confidence. Ninety-two percent of all subjects indicated they agree or strongly agree that after participating in this program they possess the skills and required knowledge that will allow him/her to confidently seek out surgical experiences in the future. 


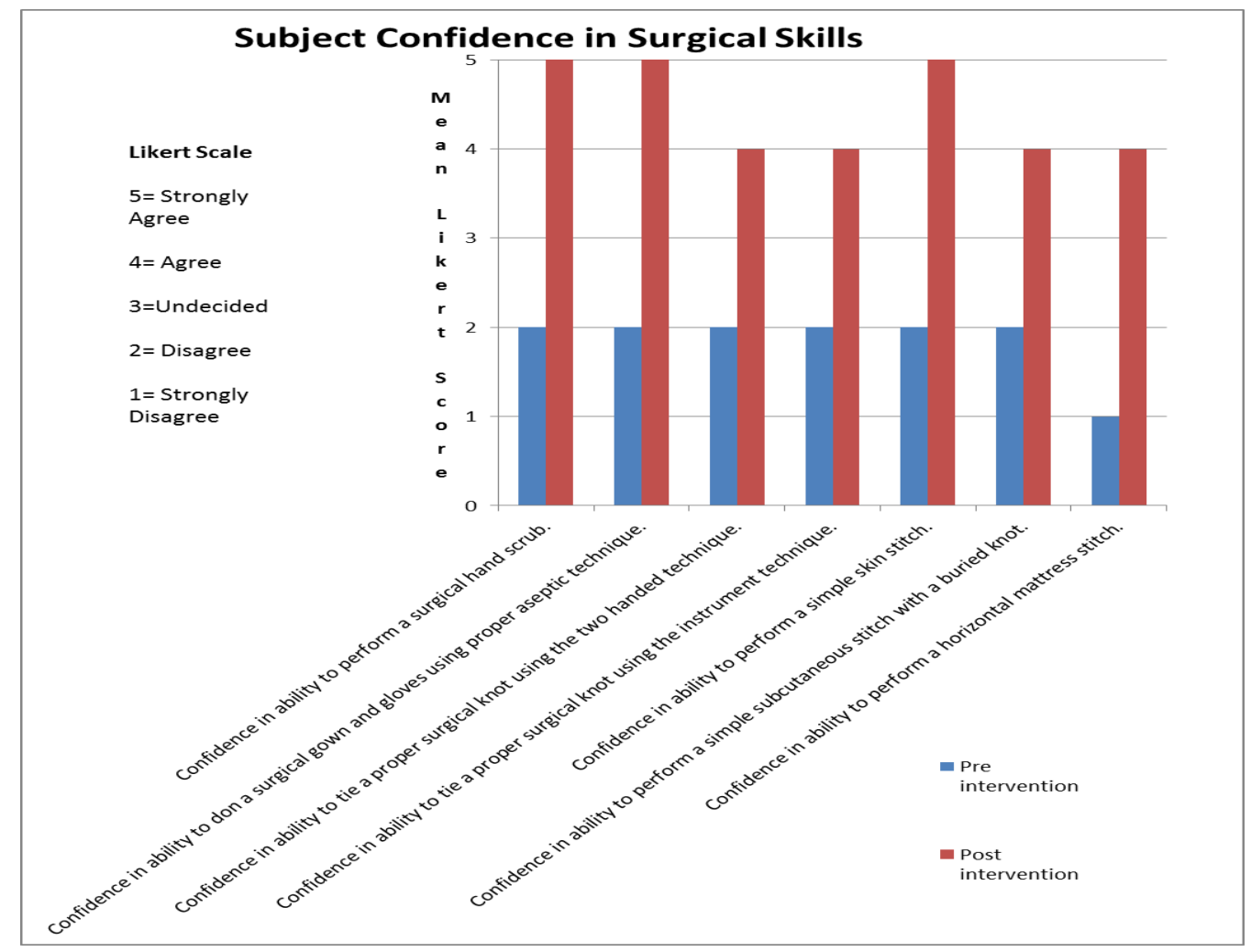

Figure 2. Subject confidence in surgical skills.

The data gathered during the survey demonstrated that there was great interest in furthering knowledge and skills necessary to practice in a surgical setting among subjects. The interest was evident both pre intervention and post intervention. The high level of interest can be credited with much of the program's success. Knowles theory of andragogy identifies that as a person matures, motivation to learn is stimulated internally rather than externally in the individual. The subjects all agreed that the skills and knowledge acquired during the program would be beneficial in practice areas other than surgery which is another important factor in adult learning. The adult learner, including the graduate nursing student, holds high regard for information that can be obtained and 
utilized immediately in practice. The program successfully fulfilled graduate nursing student's educational needs that were otherwise going to be left negated.

\section{Limitations}

There were two identified limitations in relation to the surgical skills program. Time was the greatest limitation identified by the student researcher. Psychomotor skills are typically learned and perfected through repetition over time. The program was designed to occupy a single eight hour day of the participant's time. The single day design was determined by the student researcher to be an adequate amount of time in which to introduce and practice planned activities. Subjects were encouraged to take their newly acquired knowledge and skills and practice on their own time in the future to attain mastery.

A second limitation identified was the high participant to instructor ratio. Day one resulted in four participants and one instructor. A ratio of 4:1was found to be relaxed and conducive to both the participant's learning as well as the student researcher's instruction. Day two of the program resulted in nine participants and one instructor. The 9:1 ratio was found to be difficult. The skills being presented were technically challenging and participants were in constant need of reinforcement. All participants did receive equal amount of support and instruction during the program. The student researcher did observe times in which participants were waiting for assistance rather than practicing particular skills. Ultimately, the student researcher determined that time could have been utilized more optimally if there was either a second instructor on day two or if the group was split in half. 


\section{Recommendations and Implications for Advanced Nursing Practice}

Success of an educational program should not be determined solely on data gathered during a survey. True success should be judged on how subjects take their new found knowledge and apply it during clinical rotations and future professional practice. Participants of the program are now utilizing the skills and knowledge attained and seeking out opportunities that once might have been thought impossible. Two students in particular are currently participating in surgical clinical rotations. As a result of the program and knowledge attained the two students have had opportunities to "scrub in" on multiple surgical procedures. When questioned during the semester both students have had the confidence to proclaim that they possesses the knowledge necessary to perform a surgical hand scrub and don surgical attire. Not only were the students allowed to "scrub in", they have also participated in the wound closure. Both students determined that having previous knowledge and experience is what enabled them to actively participate in surgical procedures during their final clinical rotation.

Nursing education, including graduate schools of nursing, as a whole fall short of delivering the theory and skills necessary to function effectively within a perioperative environment. The reasons for the phenomenon are numerous and answering the question adequately would necessitate a whole new research endeavor. As evidenced by the data gathered in the student researcher's program, surgical skills are a topic of great interest among graduate nursing students attending RIC. Interest should not be the sole motivator of a program. Information gained during an educational program should be applicable in more than one setting in order to fulfill the needs of the most number of participants. 
Participants agreed that the student researcher's program addressed theory and skills that are transferable to areas of practice other than surgery. The skill of surgical hand scrub is extremely important in the perioperative environment however could also be useful in other specialties such as the cardiac catheterization lab, interventional radiology, and trauma room in the emergency department. Donning surgical attire and maintaining a sterile field is necessary while performing many invasive procedures on the floor or intensive care units and not exclusive to the perioperative area. Procedures of this nature include external ventricular drains, central lines, arterial lines, chest tubes, and joint aspiration. Basic suturing skills are also useful in many areas of practice. The emergency department, walk in urgent care centers, and primary care offices routinely close lacerations. In the hospital suturing is necessary in surgical wound closure, closing groin incisions in the cardiac catheterization lab, and securing lines in the ICU.

The student researcher encourages the RIC SON to continue this program as developed. The student researcher believes the program would be most beneficial prior to the start of the graduate student's senior year. The program would then enable students to utilize skills learned during two consecutive clinical rotations prior to entry into professional practice. The student researcher would also encourage the RIC SON to build upon the program in the future. Small steps to consider might include the addition of psychomotor skills such as local anesthetic administration, incision and drainage of abscesses, debridement of minor wounds, joint aspiration, placement of radial arterial line and central line placement. These are all skills that have been identified previously in the literature as addressed in PA programs that would also be useful to the ACNP (Bednar et 
al., 2007). The student researcher also proposes that the RIC SON develop a graduate level elective class that comprises a perioperative focus. There is no graduate school within the state of Rhode Island currently offering a perioperative educational experience. The class itself could potentially attract new students, students attending other institutions, as well as professionals considering expanding their current practice. Taking steps such as these are critical to the future of the ACNP seeking to practice in a perioperative setting. Providing ACNP students with perioperative knowledge and surgical skill experiences will level the playing field with many of the PA programs and make the ACNP both more marketable and attractive to surgical practices.

The surgical skills program was deemed a success by the student researcher. Both the survey data and participant comments illustrate the program's objectives were met. Participants now possess the confidence to utilize attained knowledge and skills during clinical rotations and have new found interest in the surgical area of practice. The student researcher identified minor changes that could potentially benefit participants and strengthen the program during future administration. Changes include lower participant to instructor ratio as well as written handouts displaying specific skill instruction. The student researcher envisions a growth of the program in the future that will aid interested students entry into the professional role of surgical ACNP. 


\section{References}

Association of periOperative Registered Nurses. (2013, March). AORN position statement: advanced practice registered Nurse practicing in the perioperative setting. AORN Journal, 97, 299-301. Retrieved from http://dx.doi.org/10.1016/j.aorn.2013.01.007

Advanced Practice Registered Nurses Consensus Work Group \& the National Council of State Boards of Nursing APRN Advisory Committee. (2008). Consensus Model for APRN Regulation: Licensure, Accreditation, Certification \& Education. Retrieved from https://www.ncsbn.org/7_23_08_Consensue_APRN_Final.pdf

Accreditation Review Commission on education for the Physician Assistant. (2010). Accreditation standards for physician assistant education. Retrieved from http://www.arcpa.org/documents/Standards4theditionwithclarifyingchanges9.2013\%20FNL.pdf Advance for NPs \& PAs. (2013). Salary by practice setting. Retrieved from http://www.advanceweb.com/NPPA

Aleshire, M. E., Wheeler, K., \& Prevost, S. S. (2012). The Future of nurse practitioner practice: A world of opportunity. Nursing Clinics of North America, 47, 181-191. http://dx.doi.org/10.1016/j.cnur.2012.04.002

American Association of Colleges of Nursing. (2004). AACN Position Statement on the Practice Doctorate in Nursing October 2004 [Position statement]. Retrieved from http://www.aacn.nche.edu/publications/position/DNPpositionstatement.pdf 
Bednar, S., Atwater, A., \& Aitchison, P. (2011). Simulation for physician extenders.

Disease-A-Month, 57, 802-806. Retrieved from

http://dx.doi.org/10.1016/j.disamonth.2011.08.009

Bednar, S., Atwater, A., \& Keough, I. (2007). Educational preparation of nurse practitioners and physician assistants: An exploratory review. Advanced Emergency Nursing Journal, 29(2), 158-171. Retrieved from http://dx.doi.org/10.1097/01.TME.0000270339.19380.16

Cooper, R. A. (2007). New directions for nurse practitioners and physician assistants in the era of physician shortages. Academic Medicine, 82, 827-828. Retrieved from http://dx.doi.org/10.1097/ACM.0b013e31812f7939

Dahring, R. (2013). Predictions and resolutions for 2013. Advance for NPs \& PAs, 4(1), 9. Retrieved from http://nurse-practitioners-and-physicianassistants.advanceweb.com

Denadai, R., Oshiiwa, M., \& Saad-Hossne, R. (2012). Does bench model fidelity interfere in the acquisition of suture skills by novice medical students. Revista $d a$ Associação Médica Brasileira, 58, 600-606. Retrieved from http://dx.doi.org/10.1590/S0104-42302012000500019

Harder, N. (2010, January). Use of simulation in teaching and learning in health sciences: A systematic review. Journal of Nursing Education, 49(1), 23-28. Retrieved from http://dx.doi.org/10.3928/01484834-20090828-08 
Kelly, M. A., \& Fry, M. (2013). Masters nursing students' perceptions of an innovative simulation education experience. Clinical Simulation in Nursing, 9, e127-e133. Retrieved from http://dx.doi.org/10.1016/j.ecns.2011.11.004

Kleinpell, R. M., Hravnak, M., Werner, K. E., \& Guzman, A. (2006). Skills taught in acute care np programs: A national survey. The Nurse Practitioner, 31(2), 7, 1113. Retrieved from http://www.tnpj.com

Kleinpell, R. M., Hudspeth, R., Scordo, K. A., \& Magdic, K. (2012). Defining np scope of practice and associated regulations: Focus on acute care. Journal of the American Academy of Nurse Practitioners, 24, 11-18. Retrieved from http://dx.doi.org/10.1111/j.1745-7599.2011.00683.x

Knowles, M. S., Holton III, E. F., \& Swanson, R. A. (2005). The adult learner: The definitive classic in adult education and human resource development (6th ed.). Burlington, MA: Elsevier.

Norman, G., Dore, K., \& Grierson, L. (2012). The minimal relationship between simulation fidelity and transfer of learning. Medical Education, 46, 636-647. Retrieved from http://dx.doi.org/10.1111/j.1365-2923.2012.04243.x

Ponte, P. R., \& O’Neill, K. (2013, June). Hiring into advanced practice positions: The nurse practitioner versus physician assistant debate. The Journal of Nursing Administration, 43(6), 329-335. Retrieved from http://dx.doi.org/10.1097/NNA.0b013e3182942c73 
Rothrock, J. (2005). Competency assessment and competence acquisition: The advanced practice nurse as RN surgical first assistant. Topics in Advanced Practice Nursing eJournal, 5(1). Retrieved from http://www.medscape.com

Salary by Practice Setting. (2013). Retrieved from http://www.advanceweb.com/NPPA

Schroeder, J. L. (2008). Acute care nurse practitioner: An advanced practice role for RN first assistants. AORN Journal, 87(6), 1205-1215.

Tiffen, J., Graf, N., \& Corbridge, S. (2009). Effectiveness of a low-fidelity simulation experience in building confidence among advanced practice nursing graduate students. Clinical Simulation in Nursing, 5, e113-e117. Retrieved from http://dx.doi.org/10.1016/j.ecns.2009.01.009

W.K. Kellogg Foundation. (2004). W.K. Kellogg Foundation logic model development guide. Retrieved from http://www.wkkf.org/knowledgecenter/resources/2006/02/wk-kellogg-foundation-logic-model-developmentguide.aspx

Watkins, R., Meiers, M. W., \& Visser, Y. L. (2012). A guide to assessing needs: Essential tools for collecting information, making decisions, and achieving development results. [Adobe Digital Editions version]. Retrieved from http://ryanrwatkins.com/na/A\%20Guide\%20to\%20Assessing\%20Needs\%20\%202011\%20Watkins.pdf 


\section{Appendix A}

\section{Surgical Skills Program Logic Model}

Resources

- Program facilitator with a surgical background

- RIC faculty support

- $\quad$ RIC School of Nursing skills Lab (site of program)

- Funding (Donations, RIC School of Nursing, Program facilitator)

- $\quad$ RIC graduate nursing student's time.

\section{Outcomes}

- High subject satisfaction rate

- Subject increase in confidence performing surgical hand scrub.

- Subject increase in confidence donning sterile surgical attire.

- Subject increase in confidence performing simple wound closures.

- Increase in confidence in subject own ability to gain
Activities

- Seek IRB approval

- $\quad$ Promote the program (coordination of convenient time)

- Procure supplies

- Educational intervention focusing on surgical skills.

- $\quad$ Pre and post intervention survey.

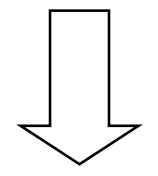

Outputs

- 2 surgical skill labs including a low-fidelity simulation experience.( Two options for subject convenience purposes as well as to decrease class size)

- High subject attendance rate $(20 / 20)$

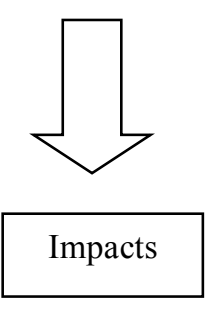

- Program will provide skills that are transferrable to many professional settings other than surgery.

- Greater number of APRNs will have the confidence to seek additional training and professional employment in a surgical setting.

- New graduates practicing in the surgical setting will provide clinical placements for future RIC graduate nursing students that possess an interest in surgery.

- $\quad$ RIC SON will consider continuing the program in the future and possibly expanding the program to a 


\section{Appendix B}

\section{Advertisement Flyer}

\section{Tentative DATES}
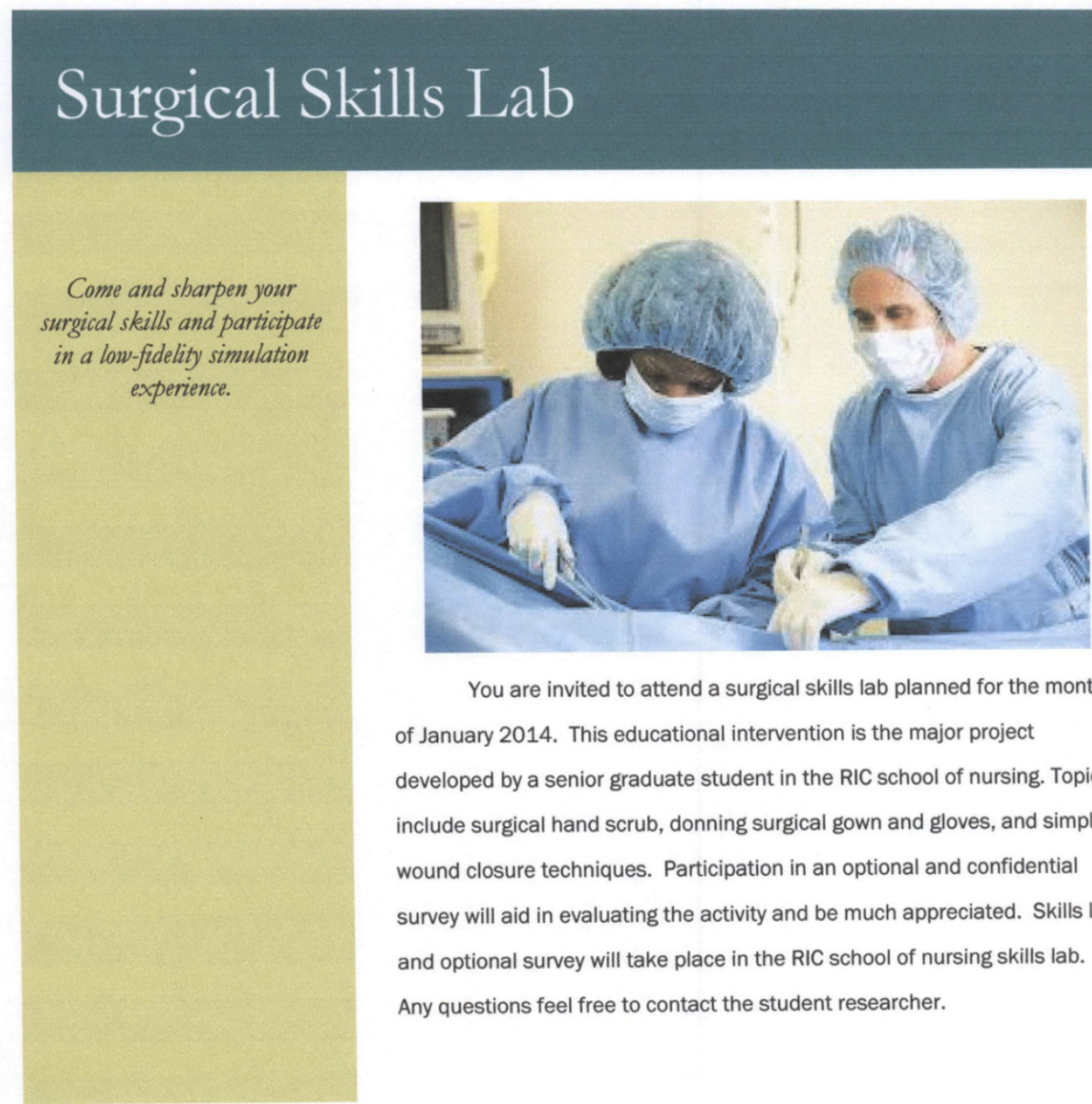

You are invited to attend a surgical skills lab planned for the month of January 2014. This educational intervention is the major project developed by a senior graduate student in the RIC school of nursing. Topics include surgical hand scrub, donning surgical gown and gloves, and simple wound closure techniques. Participation in an optional and confidential survey will aid in evaluating the activity and be much appreciated. Skills lab and optional survey will take place in the RIC school of nursing skills lab. Any questions feel free to contact the student researcher.

Tentative Dates

$$
\begin{aligned}
& 01 / ? ? / 14 \\
& 01 / ? ? / 14 \\
& 01 / ? ? / 14 \\
& 01 / ? ? / 14
\end{aligned}
$$

Student researcher contact info: Jason Heath RN, BSN, CRNFA E-mail: jheath_9017@ric.edu
Please return this portion to the student researcher with the date or dates that are most convenient.

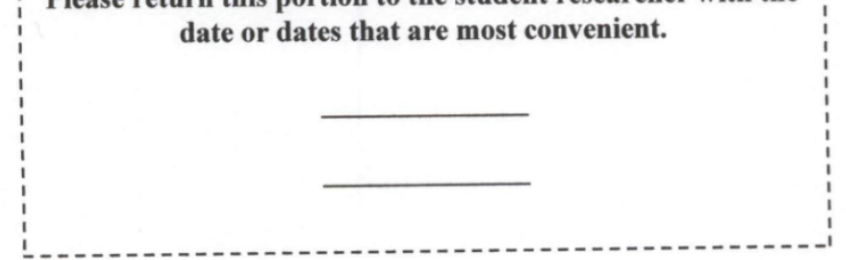




\title{
Appendix C
}

\author{
Pre-Intervention Survey
}

Control \#

\section{Surgical Skills Lab and Low-Fidelity Simulation Experience Pre-Intervention Self-Confidence Survey}

Instructions: This survey is voluntary and confidential. Do not in any way mark your survey in a manner that could possibly identify yourself. Please circle your answer to each question. Answering each question in a truthful manner and to the best of your ability is critical to the outcome of this project. Your participation is most appreciated!

KEY: 1 = Strongly Disagree

$$
\begin{aligned}
& 2=\text { Disagree } \\
& 3=\text { Undecided } \\
& 4=\text { Agree } \\
& 5=\text { Strongly Agree }
\end{aligned}
$$

\begin{tabular}{|l|c|c|c|c|c|}
\hline \multicolumn{1}{|c|}{ Survey Questions } & SD & $\boldsymbol{D}$ & $\boldsymbol{U}$ & $\boldsymbol{A}$ & $\boldsymbol{S A}$ \\
$\begin{array}{l}\text { 1.) I have an interest in gaining further knowledge and } \\
\text { skills necessary to practice in a surgical area. }\end{array}$ & 1 & 2 & 3 & 4 & 5 \\
$\begin{array}{l}\text { 2.) I am confident in my ability to perform a surgical hand } \\
\text { scrub. }\end{array}$ & 1 & 2 & 3 & 4 & 5 \\
$\begin{array}{l}\text { 3.) I am confident in my ability to don a surgical gown and } \\
\text { gloves using proper aseptic techniques. }\end{array}$ & 1 & 2 & 3 & 4 & 5 \\
$\begin{array}{l}\text { 4.) I am confident in my ability to tie a proper surgical knot } \\
\text { using the two hand technique. }\end{array}$ & 1 & 2 & 3 & 4 & 5 \\
$\begin{array}{l}\text { 5.) I am confident in my ability to tie a proper surgical knot } \\
\text { using the instrument technique. }\end{array}$ & 1 & 2 & 3 & 4 & 5 \\
$\begin{array}{l}\text { 6.) I am confident in my ability to perform a simple skin } \\
\text { stitch. }\end{array}$ & 1 & 2 & 3 & 4 & 5 \\
$\begin{array}{l}\text { 7.) I am confident in my ability to perform a simple } \\
\text { subcutaneous stitch with a buried knot. }\end{array}$ \\
$\begin{array}{l}\text { 8.) I am confident in my ability to perform a horizontal } \\
\text { mattress stitch. }\end{array}$
\end{tabular}




\title{
Appendix D
}

\author{
Post-Intervention Survey
}

Control \#

\section{Surgical Skills Lab and Low-Fidelity Simulation Experience Post-Intervention Self-Confidence Survey}

Instructions: This survey is voluntary and confidential. Do not in any way mark your survey in a manner that could possibly identify yourself. Please circle your answer to each question. Answering each question in a truthful manner and to the best of your ability is critical to the outcome of this project. Your participation is most appreciated!

KEY: $1=$ Strongly Disagree

$$
\begin{aligned}
& 2=\text { Disagree } \\
& 3=\text { Undecided } \\
& 4=\text { Agree } \\
& 5=\text { Strongly Agree }
\end{aligned}
$$

Program Evaluation:

\section{Survey Questions}

1.) I have an interest in gaining further knowledge and skills necessary to practice in a surgical area.

2.) I am confident in my ability to perform a surgical hand scrub.

3.) I am confident in my ability to don a surgical gown and gloves using proper aseptic techniques.

4.) I am confident in my ability to tie a proper surgical knot using the two hand technique.

5.) I am confident in my ability to tie a proper surgical knot using the instrument technique.

6.) I am confident in my ability to perform a simple skin stitch.

7.) I am confident in my ability to perform a simple subcutaneous stitch with a buried knot.

8.) I am confident in my ability to perform a horizontal mattress stitch.

9.) I possess skills and required knowledge that will allow me to confidently seek out surgical experiences in future clinical rotations or professional practice.

\begin{tabular}{|c|c|c|c|c|}
\hline $\boldsymbol{S D}$ & $\boldsymbol{D}$ & $\boldsymbol{U}$ & $\boldsymbol{A}$ & $\boldsymbol{S} \boldsymbol{A}$ \\
1 & 2 & 3 & 4 & 5 \\
1 & 2 & 3 & 4 & 5 \\
1 & 2 & 3 & 4 & 5 \\
1 & 2 & 3 & 4 & 5 \\
1 & 2 & 3 & 4 & 5 \\
1 & 2 & 3 & 4 & 5 \\
1 & 2 & 3 & 4 & 5 \\
1 & 2 & 3 & 4 & 5 \\
1 & 2 & 3 & 4 & 5 \\
& & & & \\
\hline
\end{tabular}

1.) I believe that the program utilized appropriate resources and methods in the facilitation of learning?

YES or NO

2.) I believe that the skills and knowledge acquired today will be beneficial in practice areas other than surgery? YES or NO

3.) Please write any comments or criticism of this program on the reverse side of the page. 
